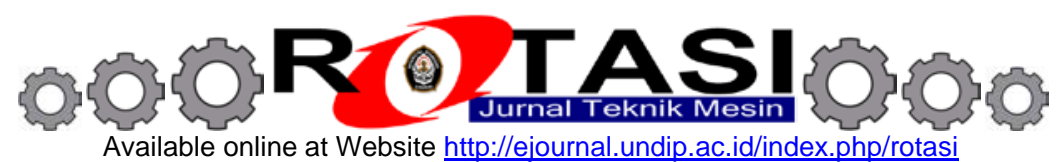

\title{
Pengujian Mampu Las Baja Karbon Astm A36 dengan Proses Las Busur Listrik
}

\author{
*Rusnaldy, Muhammad Erfas Maulana \\ Departemen Teknik Mesin, Fakultas Teknik, Universitas Diponegoro \\ Jl. Prof. Soedarto, SH, Kampus Undip Tembalang, Semarang 50275 \\ *E-mail: rusnaldy@undip.ac.id
}

\begin{abstract}
Abstrak
Proses pengelasan busur listrik dengan elektroda terbungkus (Shielded Metal Arc Welding-SMAW) banyak digunakan dalam aplikasi di industri dan konstruksi. Material yang juga banyak digunakan dalam aplikasi proses SMAW adalah baja karbon ASTM A36, yaitu jenis plain carbon steel. Kemampuan baja tersebut untuk disambung dengan menggunakan proses SMAW (weldability) dipengaruhi oleh banyak hal, salah satunya adalah heat input. Besarnya heat input pada proses pengelasan tergantung dari besarnya arus yang digunakan. Pada studi ini akan diteliti pengaruh besarnya arus yang digunakan, yaitu 70 A, 80 A dan 90 A, terhadap mampu las baja karbon ASTM A36. Metode yang digunakan untuk mengetahui mampu las baja tersebut adalah Controlled Thermal Severity (CTS) Test. Kawat elektroda yang digunakan adalah kawat elektroda terbungkus jenis E6013. Hasil yang diperoleh dari pengujian ini adalah mampu las baja ASTM A36 cukup baik. Hal ini diindikasikan dengan jumlah dan ukuran dari retak yang ditemukan masih di bawah harga minimum yang dipersyaratkan. Kemudian juga diketahui bahwa makin besar arus listrik yang digunakan menyebabkan peningkatan nilai kekerasan mikro dari logam las dan HAZ, namun jumlah dan ukuran retak jadi bertambah banyak dan besar.
\end{abstract}

Kata kunci: Heat Input, kekerasan mikro, mampu las, pengelasan, retak.

\section{Pendahuluan}

Shielded Metal Arc Welding (SMAW) atau proses pengelasan busur listrik merupakan cara pengelasan dengan menggunakan kawat elektroda yang terbungkus dengan fluks. Selama proses pengelasan bahan fluks yang digunakan untuk membungkus elektroda mencair dan membentuk terak dan gas yang kemudian menutupi dan melindungi logam cair yang terkumpul di tempat sambungan dan bekerja sebagai penghalang oksidasi [1]. SMAW dapat digunakan di hampir seluruh logam dan paduan terutama untuk mengelas semua jenis baja baik baja karbon, baja paduan rendah, maupun baja tahan karat. SMAW biasa digunakan dalam pengelasan bejana tekan, pipa minyak dan gas alam, tanki bahan bakar, jembatan, konstruksi gedung, perakitan kapal, truk, mobil, dan seluruh produk yang terbuat dari besi cor. Selain itu,karena penggunaannya yang mudah dibanding jenis pengelasan lain, serta peralatan yang sederhana, dan kemampuan untuk digunakan pada segala posisi membuat SMAW menjadi pilihan pengelasan yang paling umum digunakan di dunia saat ini.

Pada studi ini digunakan baja karbon ASTM A36 yang termasuk dalam kategori baja karbon rendah jenis plain carbon steel yang banyak digunakan di industri dan kontruksi. Berbeda dengan baja paduan yang ditambahkan paduan lain dalam konsentrasi tertentu untuk menaikan sifat mekanik dan meningkatkan ketahanan korosi, baja ini hanya berisi karbon dan sedikit mangan serta pengotor [2]. Baja ini mempunyai kepekaan terhadap retak las yang rendah bila dibandingkan dengan baja karbon jenis lainnya [3]. Untuk menguji mampu las baja karbon ASTM A36, metode Controlled Thermal Severity (CTS) Test digunakan untuk mengetahui efek pengelasan dan masukan panas pengelasan (heat input) yang sangat dipengaruhi oleh besarnya arus listrik yang digunakan [4].

Sehingga secara khusus tujuan pada studi ini adalah untuk mengetahui mampu las (weldability) baja karbon ASTM A36 berbentuk pelat jika disambung dengan proses las SMAW dengan menggunakan kawat elektroda terbungkus. Parameter pengelasan yang dijadikan sebagai variabel adalah arus las, yakni sebesar 70 A, 80 A dan 90 A. Metode yang digunakan untuk menguji mampu las adalah metode Controlled Thermal Severity (CTS) Test. Mampu las diketahui dengan mengamati adanya retak setelah proses pengelasan, besarnya kecembungan (convexity), jumlah dan besarnya retak yang terjadi serta nilai kekerasan yang dihasilkan pada logam las dan HAZ.

\section{Material dan metodologi}

\subsection{Material Benda Kerja}

Material benda kerja yang digunakan dalam pengujian ini adalah baja karbon rendah ASTM A36 berbentuk pelat yang dibuat menjadi dua ukuran, yaitu 80 × 80 × 4 mm dan 260 x 100 x 4 mm yang kemudian disatukan dengan menggunakan baut (lihat gambar 1). Komposisi kimia dari pelat ini dapat dilihat pada tabel 1. Sementara sifat mekaniknya yaitu kekuatan tarik dan kekuatan luluhnya sebesar berturut-turut $400 \mathrm{MPa}$ dan $250 \mathrm{MPa}$. 
Tabel 1. Komposisi Kimia Baja ASTM A36 [5]

\begin{tabular}{|c|c|c|c|c|c|}
\hline Unsur & $\mathrm{C}$ & $\mathrm{P}$ & $\mathrm{S}$ & $\mathrm{Si}$ & $\mathrm{Cu}$ \\
\hline \% Berat & 0,25 & 0,04 & 0,05 & 0,04 & 0,2 \\
\hline
\end{tabular}

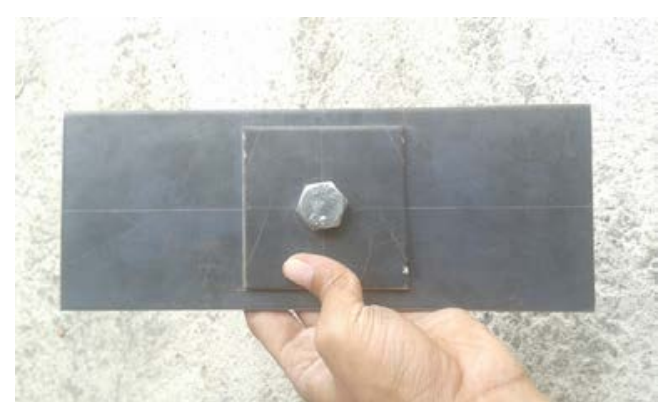

Gambar 1. Benda kerja

\subsection{Pengujian Mampu Las}

Pengujian mampu las yang dilakukan didasarkan pada AWS B4.0 -98. Metode pengujian yang dipilih adalah Controlled Thermal Severity (CTS). Detil urutan pengujian mampu las dapat dilihat pada AWS tersebut [4]. Mesin las yang digunakan pada pengujian ini adalah mesin las listrik AC merek Rilon Model ARC 160 yang dapat diatur arus listriknya dari 30 A sampai 160 A. Kawat elektroda yang digunakan adalah kawat elektroda tipe E6013 [6]. Proses pengelasan yang dilakukan dapat dilihat pada gambar 2a dan dan proses pendinginannya dapat dilihat pada gambar $2 \mathrm{~b}$. Proses pendinginan dilakukan selama 72 jam untuk setiap sisi yang dilas.

Setelah didinginkan, jika tidak ditemukan adanya cacat yang terjadi di permukaan las, seperti retak yang dapat diamati secara visual, maka hasil lasan kemudian dibagi menjadi 4 bagian (lihat gambar 3) untuk diamati retak yang terdapat di bagian dalam dengan menggunakan mikroskop dan juga dilakukan pengujian kekerasan mikro di setiap daerah, yaitu pada logam induk, HAZ dan logam las.

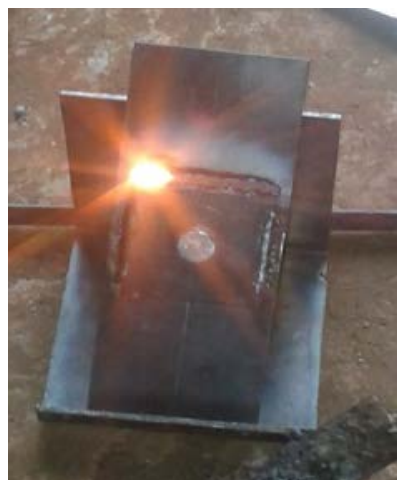

(a)

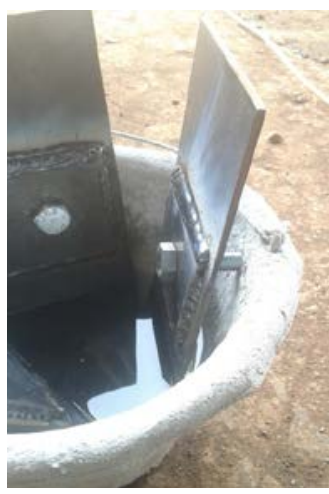

(b)

Gambar 2. (a) Proses Pengelasan, (b) Proses Pendinginan Hasil Las

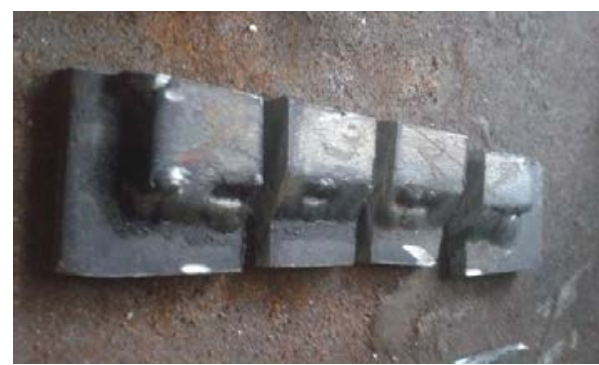

Gambar 3. Pemotongan hasil lasan menjadi 4 bagian untuk pengamatan retak dan pengujian kekerasan

\section{Hasil dan pembahasan}

Parameter proses las yang divariasikan pada studi ini adalah besarnya arus, yaitu 70, 80 dan 90 Ampere. Tabel 3 memperlihatkan hasil pengukuran rata-rata convexity atau kecembungan logam las yang diukur dengan menggunakan welding gauge. Dari hasil yang diperoleh terlihat bahwa semua hasil lasan dapat diterima, karena menurut AWS, dengan lebar las kurang dari 8 mm, maka besarnya harga maksimal convexity yang masih diijinkan adalah 1,6 mm, sementara semua lasan memiliki convexity di bawah $1 \mathrm{~mm}$ [7]. 
Tabel 3. Hasil Pengukuran Convexity pada logam las

\begin{tabular}{cc}
\hline Arus (Ampere) & Convexity (mm) \\
\hline 70 & 0,125 \\
80 & 0,83 \\
90 & 0,75 \\
\hline
\end{tabular}

Gambar 4, 5 dan 6 memperlihatkan struktur mikro pada logam induk, HAZ dan logam las pada perbesaran 5x pada proses pengelasan dengan menggunakan arus sebesar 70 A, 80 A dan 90 A. Pengamatan adanya retak dilakukan pada foto-foto struktur tersebut. Dari gambar 4 terlihat bahwa retak ditemukan pada daerah HAZ, sementara pada logam induk dan logam las tidak ditemukan adanya retak. Pada gambar 5, retak ditemukan pada HAZ (gambar 5b) dan logam las (gambar 5c). Sementara itu pada proses pengelasan dengan menggunakan arus 90 A, retak juga ditemukan pada HAZ dan logam las (lihat gambar 6a dan 6b)

Pengukuran panjang retak dilakukan pada struktur mikro yang terdapat retak dengan perbesaran 50x. Contoh pengukuran retak dapat dilihat pada gambar 7. Hasil pengukuran retak berupa jumlah retak yang ditemukan dan panjang retak dapat dilihat pada tabel 4, 5 dan 6. Semua retak yang ditemukan masih dapat diterima karena panjangnya kurang dari $5 \%$ dari leg length $(5 \%$ x $4000 \mu \mathrm{m}=200 \mu \mathrm{m})$. Dari hasil ini dapat dikatakan bahwa semua proses pengelasan memiliki hasil "not cracked” dan selanjutnya dapat dilakukan pengujian kekerasan mikro.

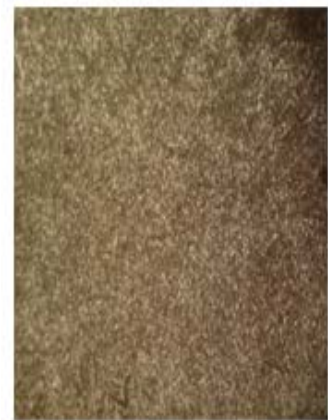

(a)

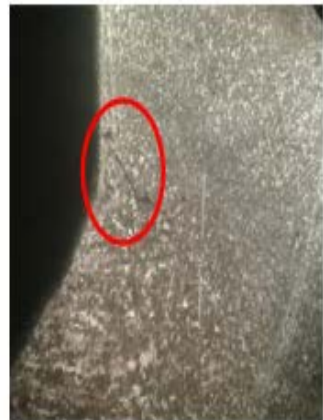

(b)

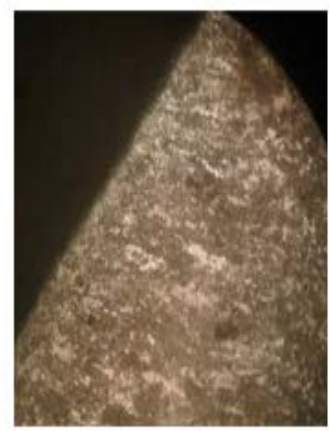

(c)

Gambar 4. Pengamatan a) daerah logam induk, b) HAZ, c) daerah logam las, hasil las dengan arus $70 \mathrm{~A}$

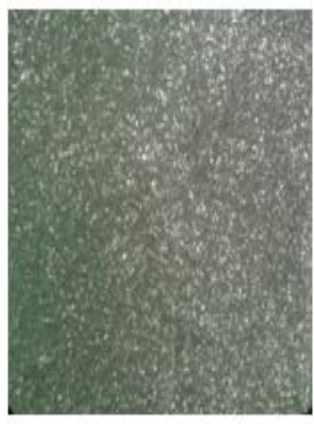

(a)

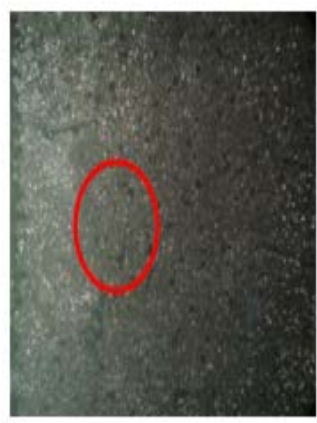

(b)

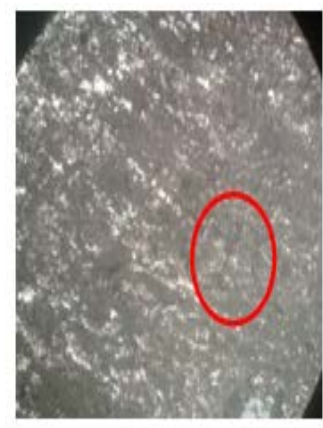

(c)

Gambar 5. Pengamatan a) daerah logam induk, b) HAZ, c) daerah logam las, hasil las dengan arus $80 \mathrm{~A}$

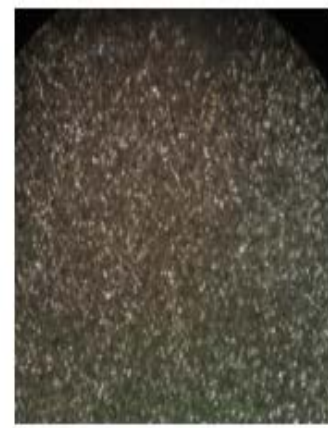

(a)

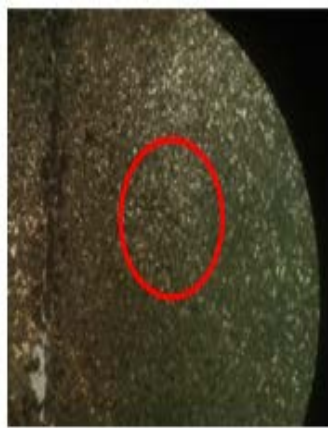

(b)

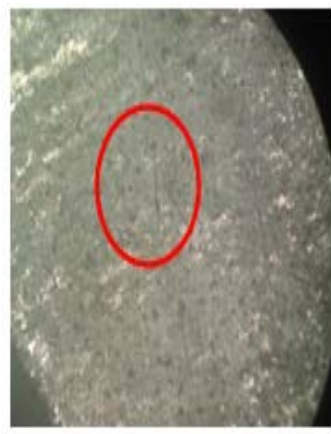

(c)

Gambar 6. Pengamatan a) daerah logam induk, b) HAZ, c) daerah logam las, hasil las dengan arus 90 A 


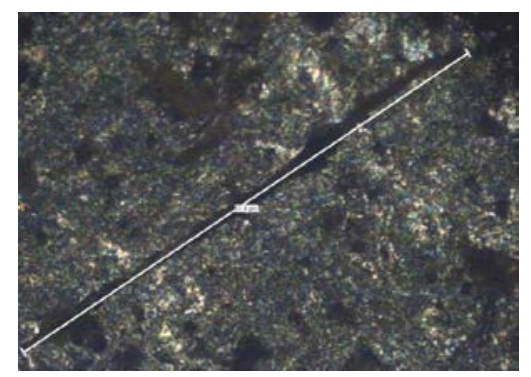

Gambar 7. Pengukuran panjang retak

Tabel 4. Jumlah dan panjang retak yang ditemukan pada hasil las dengan arus $70 \mathrm{~A}$

\begin{tabular}{|c|c|c|c|c|c|}
\hline \multirow{2}{*}{ Arus } & \multirow{2}{*}{ Sisi } & \multicolumn{3}{|c|}{ Crack di Daerah } & \multirow{2}{*}{ Panjang Crack } \\
\cline { 3 - 5 } & & Logam Induk & HAZ & Logam Las & Maksimum $(\mu \mathrm{m})$ \\
\hline \multirow{6}{*}{$70 \mathrm{~A}$} & 1 & - & - & - & - \\
\cline { 2 - 5 } & 2 & - & - & - & - \\
\cline { 2 - 5 } & 3 & - & - & - & - \\
\cline { 2 - 5 } & 4 & - & - & - & - \\
\cline { 2 - 5 } & 5 & - & 1 & - & 36,1 \\
\cline { 2 - 5 } & 6 & - & - & - & - \\
\hline \multicolumn{2}{|c|}{ Jumlah } & 0 & 1 & 0 & \\
\hline
\end{tabular}

Tabel 5. Jumlah dan panjang retak yang ditemukan pada hasil las dengan arus $80 \mathrm{~A}$

\begin{tabular}{|c|c|c|c|c|c|}
\hline \multirow{2}{*}{ Arus } & \multirow{2}{*}{ Sisi } & \multicolumn{3}{|c|}{ Crack di Daerah } & \multirow{2}{*}{ Panjang Crack } \\
\cline { 3 - 5 } & & Logam Induk & HAZ & Logam Las & Maksimum $(\mu \mathrm{m})$ \\
\hline \multirow{5}{*}{ 80 A } & 1 & - & - & - & - \\
\cline { 2 - 5 } & 2 & - & 1 & - & 55,5 \\
\cline { 2 - 5 } & 3 & - & 1 & 1 & 49,1 \\
\cline { 2 - 5 } & 4 & - & - & - & - \\
\cline { 2 - 5 } & 5 & - & 1 & - & 28,1 \\
\cline { 2 - 5 } & 6 & - & - & - & - \\
\hline \multicolumn{2}{|c|}{ Jumlah } & 0 & 3 & 1 & \\
\hline
\end{tabular}

Tabel 6. Jumlah dan panjang retak yang ditemukan pada hasil las dengan arus 90 A

\begin{tabular}{|c|c|c|c|c|c|}
\hline \multirow{2}{*}{ Arus } & \multirow{2}{*}{ Sisi } & \multicolumn{3}{|c|}{ Crack di Daerah } & \multirow{2}{*}{\begin{tabular}{c} 
Panjang Crack \\
\cline { 2 - 5 }
\end{tabular}} \\
\cline { 2 - 6 } & Logam Induk & HAZ & Logam Las & Maksimum $(\mu \mathrm{m})$ \\
\hline \multirow{5}{*}{$90 \mathrm{~A}$} & 1 & - & - & - & - \\
\cline { 2 - 6 } & 2 & - & 2 & 1 & 51,4 \\
\cline { 2 - 6 } & 3 & - & - & 1 & 45,8 \\
\cline { 2 - 6 } & 4 & - & 1 & - & 46,6 \\
\cline { 2 - 6 } & 5 & - & - & - & - \\
\cline { 2 - 6 } & 6 & - & - & - & - \\
\hline \multicolumn{2}{|c|}{ Jumlah } & 0 & 3 & 2 & \\
\hline
\end{tabular}

Tabel 7. Hasil Uji Kekerasan Vickers

\begin{tabular}{|c|c|c|c|}
\hline \multirow{2}{*}{ Daerah } & \multicolumn{3}{|c|}{ Kekerasan (HV) } \\
\cline { 2 - 4 } & Arus 70 A & Arus 80 A & Arus 90 A \\
\hline $\begin{array}{c}\text { Logam } \\
\text { Las }\end{array}$ & 160 & 166 & 172 \\
\hline HAZ & 137 & 140,33 & 141,83 \\
\hline $\begin{array}{c}\text { Logam } \\
\text { Induk }\end{array}$ & 118 & 117,5 & 118,33 \\
\hline
\end{tabular}

Hasil uji kekerasan pada tiga daerah las untuk hasil proses pengelasan dengan menggunakan arus 70 hingga 90 Ampere dapat dilihat pada tabel 7. Dari tabel 7 tersebut terlihat bahwa kekerasan tertinggi dicapai pada logam las dan 
diikuti oleh HAZ dan logam induk. Hasil ini menunjukkan bahwa proses pengelasan memiliki hasil yang baik dimana sambungan las memiliki kekuatan yang lebih besar dibanding logam yang disambung [8]. Dari tabel juga dapat dilihat bahwa makin besar arus yang digunakan kekerasan logam las dan HAZ meningkat. Namun jika dibandingkan dengan pengamatan retak yang terjadi menunjukkan bahwa meningkatnya arus yang digunakan menyebabkan jumlah dan ukuran retak yang ditemukan juga meningkat.

\section{Kesimpulan}

Dari hasil yang diperoleh maka dapat ditarik kesimpulan sebagai berikut: (1) Proses las busur listrik pada baja karbon ASTM A36 dengan menggunakan arus listrik sebesar 70 hingga 90 Ampere menghasilkan kualitas las yang baik, (2) Makin besar arus listrik yang digunakan disamping meningkatkan nilai kekerasan Vickers pada logam las dan HAZ, namun juga menambah jumlah serta ukuran retak yang terjadi,

\section{Referensi}

[1] Wiryosumarto, H. 2000. TeknologiPengelasanLogam- Cetakan ke-8. Jakarta: PradyaParamita

[2] Callister, W.D. 2007. Material Science and Engineering: An Introduction - 7 Ed. New York: John Wiley \& Sons, Inc.

[3] Kou, S, 2003. Welding Metallurgy, 2nd Ed. New Jersey: John Wiley \& Sons, Inc.

[4] AWS B4.0-98, 1999. Standard Methods for Mechanical Testing of Weld, 62-69. Miami Florida: American Welding Standard

[5] ASTM, 2005, Standard Specification for Carbon Structural Steel - A36. Pennsylvania: ASTM International.

[6] AWS A5.1. 1991. Standart Specification for Standart Carbon Steel Electrodes for Shield Metal Arc Welding. Miami Florida: American Welding Standard

[7] AWS, 1996. The Everyday Pocket Handbook for Visual Inspection and Weld Discontinuities - Causes and Remedies. Miami Florida: American Welding Standard.

[8] ASM. 1990. ASM Handbook Vol 1, Properties and Selection: Irons, Steels, and High Performance Alloy. Ohio: ASM International. 